\title{
Low-cost biochar derived from herbal residue: characterization and application for ciprofloxacin adsorption
}

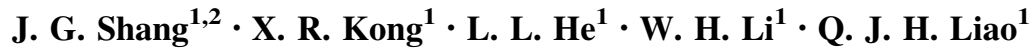

Received: 11 January 2016/Revised: 12 May 2016/Accepted: 19 July 2016/Published online: 10 August 2016

(C) Islamic Azad University (IAU) 2016

\begin{abstract}
Thermally carbonization biochar produced from a traditional Chinese herbal medicine waste (Astragalus mongholicus residue) was investigated for its performance in ciprofloxacin adsorption. Batch sorption experiments were conducted, and scanning electron microscopy, Fourier transform infrared spectroscopy, X-ray photoelectron spectroscopy and Brunauer-Emmett-Teller surface area analyses were employed to characterize the biochar. The results demonstrated that thermal activation process improves the adsorbent characteristics. Biochar produced at $800{ }^{\circ} \mathrm{C}$ had the best adsorption capacity, a better pore structure and the largest surface areas. The adsorption process fit well to a pseudo-second-order kinetics model. The adsorption isothermal model results revealed that the adsorption process of ciprofloxacin is described better by the Freundlich isotherm and the type of adsorption is a chemical process. The maximum adsorption of ciprofloxacin occurred at $\mathrm{pH}$ 7. The present research demonstrated that A. mongholicus biochar might be an attractive and cost-effective adsorbent with good adsorption performance for removing ciprofloxacin from water solution.
\end{abstract}

Q. J. H. Liao

liaoqianjiahua@163.com

1 Department of Environmental Science, China Pharmaceutical University, Nanjing 210009, People's Republic of China

2 State Key Laboratory of Lake Science and Environment, Nanjing Institute of Geography and Limnology, Chinese Academy of Sciences, Nanjing 210008, People's Republic of China
Keywords Removal Antibiotic - Biomass waste - Water · Carbonization

\section{Introduction}

In recent years, antibiotics, including sulfonamides (SAs), quinolones (QNs), macrolides (MCs), tetracyclines (TCs) and $\beta$-lactams, have been used extensively to prevent or treat infective diseases in human or animals (Thiele-Bruhn 2003). However, many antibiotics cannot be absorbed completely or metabolized. The by-products are released into the ground or drinking water and adversely affect human health as well as the environment, becoming pseudo-persistent in the environment (Wang et al. 2014; Zhou and Broodbank 2014).

Previous researchers have reported the presence of antibiotics in water bodies, such as rivers, lakes and oceans at concentrations ranging from $\mathrm{ng} / \mathrm{L}$ to $\mu \mathrm{g} / \mathrm{L}$. Sulfonamides were the dominant antibiotics found in surface water (Wang et al. 2014). Zhang et al. (2015) used market survey, data analysis and modeling methods to estimate that approximately 53,800 tons of 36 antibiotic chemicals entered the environment in China following various types of wastewater treatment. Various treatment methods, including physical adsorption (Carabineiro et al. 2012), bio-sorption, chemical degradation methods, such as advanced oxidation and ozonation (Gao et al. 2014) and biological degradation (Qiu et al. 2013), have been used for the treatment of antibiotics.

Several degradation products of antibiotics were shown to be more toxic to organisms than their parent antibiotics. For example, N4-acetyl sulfamethazine, which is one of the metabolites of sulfamethazine, proved to be more hazardous than its parent compound (Le-Minh et al. 2012). 
Therefore, the treatment techniques for antibiotic pollutants must be highly effective and prevent secondary contamination. Compared with other treatment techniques, adsorption is more effective because of its simplicity in design, ease of handling and ability to overcome secondary pollutants. Commercial activated carbon (AC) is considered as an excellent adsorbent with a higher adsorption capacity for a large Brunauer-Emmett-Teller (BET) surface area (Ali et al. 2012). However, the cost of AC is high and prevents its wide application, especially in developing countries. As a consequence, developing a highly effective and low-cost adsorbent is necessary.

Biochar, which is a porous, carbon residue derived from the thermal conversion of waste biomass under limited oxygen or anaerobic conditions, is one of the most promising materials because it is more highly effective, environmentally friendly and cost-effective than other materials (Ahmad et al. 2014; Mohan et al. 2014). Biochar can be derived from a variety of materials, such as plant residue, animal waste and sludge. A large number of studies on pollutant removal focus on the use of biochar. Examples of recent research papers include the adsorption of heavy metals from wastewater (e.g., $\mathrm{Cd}, \mathrm{Cu}, \mathrm{Pb}, \mathrm{As}$ ) using sewage sludge waste or biomass biochar (Dubey et al. 2014; Chen et al. 2015; Wang et al. 2015; Komkiene and Baltrenaite 2016), the adsorption of tetracycline and fluoroquinolone using rice husk biochar, wastewater sludge biochar or cow manure biochar (Yao et al. 2013; Jing et al. 2014; Tzeng et al. 2016), the adsorption of pesticides by agricultural biomass biochar (Inyang and Dickenson 2015) and the adsorption of dye using plant waste biochar (Sun et al. 2013). Using plant waste in biochar synthesis is preferable and sustainable because plant wastes such as agricultural residues are still underutilized, and a large portion of this biomass is discarded as waste (Loow et al. 2015).

The biochar investigated in the present research is Astragalus mongholicus residue (Huangqi in China), which is a commonly used traditional Chinese herbal medicine. Several million tons of herb residue are produced in China every year, which means that the residue can easily cause a serious environmental problem. These herb residue wastes have a high lignin, cellulose and hemicellulose contents, so they are suitable for biochar production. Another advantage of this herb-biochar production is that it is an environmentally friendly and cost-effective way to treat wastewater from the medicine factory.

The aim of this study was to investigate the possibility of using A. mongholicus biochar (AMBC) as a cost-effective adsorbent for ciprofloxacin (CIP) removal from water solutions. The adsorption characteristics of CIP onto $A M B C$ were investigated under varying conditions, which included the contact times, dosages, $\mathrm{pH}$ and initial CIP concentrations. Scanning electron microscopy (SEM), Fourier transform infrared spectroscopy (FTIR) and X-ray photoelectron spectroscopy (XPS) analyses were carried out. The adsorption experiments were carried out from June to September 2015 on the laboratory scale at China Pharmaceutical University, Nanjing, China.

\section{Materials and methods}

\section{AMBC preparation and characterization}

The residue of one of the commonly used traditional Chinese herbal medicines, A. mongholicus, was washed with distilled water and dried at $105^{\circ} \mathrm{C}$ for $24 \mathrm{~h}$. The dry herb residue was ground and passed through a 100-mesh sieve. The ground herb residue was then treated via a thermal carbonization procedure as described Shang et al. (2015). The herbal residue was subjected to thermal activation for $5 \mathrm{~h}$ under oxygen-limited conditions $(200,400,500,600$, 700 and $800^{\circ} \mathrm{C}$ ). After thermal activation, the residues were washed with $0.1 \mathrm{~mol} / \mathrm{L} \mathrm{HCl}$ overnight to remove the suspended ash. Then, the biochar was washed with DI water until the $\mathrm{pH}$ was stable and dried at $105^{\circ} \mathrm{C}$ overnight.

The $S_{\mathrm{BET}}$ (BET surface area) was measured by the nitrogen sorption method at $77 \mathrm{~K}$ with a surface area and porosity analyzer (ASAP2020, Micromeritics Instrument Corp., Norcross, GA, USA). Surface functional groups were investigated by FTIR spectroscopy using a Nicolet FTIR spectrophotometer (Thermoscientific Nicolet iS10, USA), scanning from 4000 to $500 \mathrm{~cm}^{-1}$ with a resolution of $2 \mathrm{~cm}^{-1}$. The microstructure analysis of the biochar was performed with an SEM (JEOL JSM-7500F, JEOL Ltd., Tokyo, Japan). The surface chemistry of biochar was determined using an XPS spectrometer (Thermo Fisher Scientific, K-Alpha, USA) with a monochromated Al Ka source and a spot size $400 \mu \mathrm{m}$ in diameter.

\section{Preparation of ciprofloxacin solution and HPLC Conditions}

Ciprofloxacin (CAS: 85721-33-1) with purity greater than $99 \%$ was obtained from Aladdin Chemical Reagent Co. (Shanghai, China). CIP stock solution was prepared $(500 \mathrm{mg} / \mathrm{L})$ by dissolving the ciprofloxacin in DI water and storing at $4{ }^{\circ} \mathrm{C}$. The basic properties of compound are given as follows: molecular formula, $\mathrm{C}_{17} \mathrm{H}_{18} \mathrm{FN}_{3} \mathrm{O}_{3}$, and molecular weight, 331.34 .

The concentration of CIP was analyzed using high-performance liquid chromatography (HPLC) with a UV detector. Chromatographic separation was performed at $30{ }^{\circ} \mathrm{C}$ on a Waters Symmetry C18 Column $(4.6 \mathrm{~mm} \times 150 \mathrm{~mm}$, 
$5 \mu \mathrm{m}$ particle size). The mobile phase was composed of $0.05 \mathrm{~mol} / \mathrm{L}$ of citric acid solution [acetonitrile $(82: 18 \mathrm{v} / \mathrm{v})]$. The $\mathrm{pH}$ was adjusted to 3.5 with triethylamine. The flow rate was $1.0 \mathrm{~mL} / \mathrm{min}$, and the injection volume was $10 \mu \mathrm{L}$. UV measurement was taken at a wavelength of $278 \mathrm{~nm}$.

\section{Adsorption studies}

A series of adsorption experiments was performed using a Teflon tube (Nalgene, Thermol, USA). The mixture was shaken under $25{ }^{\circ} \mathrm{C}$ on a shaker at $200 \mathrm{rpm}$ and then filtered through a $0.45-\mu \mathrm{m}$ filter. In the first set of experiments, $25 \mathrm{~mL}$ CIP solution $(100 \mathrm{mg} / \mathrm{L})$ and $0.05 \mathrm{~g}$ of AMBC (produced at 200, 400, 500, 600, 700 and $800{ }^{\circ} \mathrm{C}$ ) were mixed into tubes and stirred for $12 \mathrm{~h}$ to investigate the influence of the activation temperature. Natural $A$. mongholicus residue (BC100) was set as the control. The $\mathrm{AMBC}$ results that showed the highest adsorption capacity were chosen to be used in the following experiments.

The effect of the adsorbent dosage on the removal of CIP was demonstrated in the second experiment. AMBC with the highest adsorption capacity was added to the tube containing the solution $(25 \mathrm{~mL}, 100 \mathrm{mg} / \mathrm{L}$ of CIP) and stirred for $12 \mathrm{~h}$ (dosage: $25,50,100,500 \mathrm{mg}$ ). To understand the influence of $\mathrm{pH}$ on CIP adsorption by AMBC, experiments were performed by adding $25 \mathrm{ml}$ of CIP working solution $(100 \mathrm{mg} / \mathrm{L})$ and $50 \mathrm{mg}$ AMBC to the tube and equilibrating for $12 \mathrm{~h}$. The $\mathrm{pH}$ was adjusted from 3 to 10 with $\mathrm{NaOH}$ and $\mathrm{HCl}(1 \mathrm{~mol} / \mathrm{L})$. The adsorption isotherm experiments were conducted with $50 \mathrm{mg}$ of biochar and $25 \mathrm{~mL}$ of CIP solution, with the CIP concentration ranging from 10 to $300 \mathrm{mg} / \mathrm{L}(10,25,50,100,150,200$ and $300 \mathrm{mg} / \mathrm{L}$ ). The effect of equilibration time on the adsorption was studied in the fifth set of experiments. AMBC (50 mg) and CIP solution ( $25 \mathrm{~mL}, 25,50,100,150$, $200 \mathrm{mg} / \mathrm{L}$ ) were mixed in the tube and stirred from $0 \mathrm{~h}$ to $12 \mathrm{~h}$.

\section{Adsorption isothermal and kinetics models}

Langmuir (Eq. 1), Freundlich (Eq. 2), Temkin (Eq. 3) isotherm and D-R isotherm (Eq. 4) models were used to analyze the adsorption equilibrium data in the present study.

$$
\begin{aligned}
& \frac{C_{\mathrm{e}}}{q_{\mathrm{e}}}=\frac{1}{\mathrm{k}_{\mathrm{a}} q_{\mathrm{m}}}+\frac{C_{\mathrm{e}}}{q_{\mathrm{m}}} \\
& \log q_{\mathrm{e}}=\log k_{\mathrm{f}}+\frac{\log C_{\mathrm{e}}}{n} \\
& q_{\mathrm{e}}=A \log k_{\mathrm{T}}+A \log C_{\mathrm{e}} \\
& \ln q_{\mathrm{e}}=\ln q_{\mathrm{m}}-\beta\left(R T \ln \left(1+\frac{1}{C_{\mathrm{e}}}\right)\right)^{2}
\end{aligned}
$$

where $C_{\mathrm{e}}$ is the equilibrium concentration after adsorption $(\mathrm{mg} / \mathrm{L}), q_{\mathrm{e}}$ is the amount of CIP adsorbed per gram of AMBC $(\mathrm{mg} / \mathrm{g}), k_{\mathrm{a}}(\mathrm{L} / \mathrm{mg})$ is the Langmuir constant, $q_{\mathrm{m}}$ $(\mathrm{mg} / \mathrm{g})$ is the maximum adsorption capacity of the Langmuir isotherm model, $k_{\mathrm{f}}$ is the constant indicative of the relative adsorption capacity of AMBC ( $\mathrm{mg} / \mathrm{g}), 1 / \mathrm{n}$ is the constant, $A$ is the constant related to the heat of the adsorption process $(\mathrm{J} / \mathrm{mol}), k_{\mathrm{T}}$ is the constant of the Temkin isotherm equilibrium, the parameter $\beta$ is the constant of the sorption energy $\left(\mathrm{mol}^{2} / \mathrm{J}^{2}\right), T$ is the temperature $(\mathrm{K})$ and $R$ is the gas constant $(8.314 \mathrm{~J} /(\mathrm{mol} \mathrm{K}))$.

The value of the sorption energy, $E(\mathrm{~kJ} / \mathrm{mol})$, can be calculated as follows:

$E=\frac{1}{\sqrt{2 \times \beta}}$

The value of $E$ gives information about the adsorption processes. The value ranges from 1 to $8 \mathrm{~kJ} / \mathrm{mol}$ for physical sorption and from 8 to $16 \mathrm{~kJ} / \mathrm{mol}$ for chemical sorption (Ma et al. 2015).

Linear forms of the pseudo-first-order (Eq. 6) and pseudo-second-order model (Eq. 7) were used to investigate the adsorption kinetics of CIP onto biochar:

$\log \left(q_{\mathrm{e}}-q_{\mathrm{t}}\right)=\log q_{\mathrm{e}}-k_{1} t$

$\frac{t}{q_{\mathrm{t}}}=\frac{1}{k_{2} q_{\mathrm{e}}^{2}}+\frac{1}{q_{\mathrm{e}}} t$

where $q_{\mathrm{t}}$ and $q_{\mathrm{e}}(\mathrm{mg} / \mathrm{g})$ correspond to the adsorption capacity of the biochar at time $t$ and equilibrium. The parameters $k_{1}$ and $k_{2}\left(\mathrm{~min}^{-1}\right)$ are the rate constants of the adsorption models 6 and 7 , respectively.

\section{Results and discussion}

\section{Effect of carbonization temperature}

Temperature is one of the most important factors in controlling the physicochemical properties of biochar (Ahmad et al. 2014). The carbon content rose when the pyrolysis temperature increased, whereas the $\mathrm{H}$ and $\mathrm{O}$ contents decreased; further, the surface area increased with an increase in temperature (Tzeng et al. 2016). Mui et al. (2010) concluded that the bamboo biochar produced under the higher temperature had a better adsorption capacity for dye. The present research also yielded the same conclusion as described in former studies. The removal efficiency and adsorption capacity of CIP using natural A. mongholicus residue, AMBC, were compared (Fig. 1). According to the results, the natural $A$. mongholicus residue and $\mathrm{BC} 200$ had the lowest removal performance, whereas thermal treatment at higher temperature provided a significant 


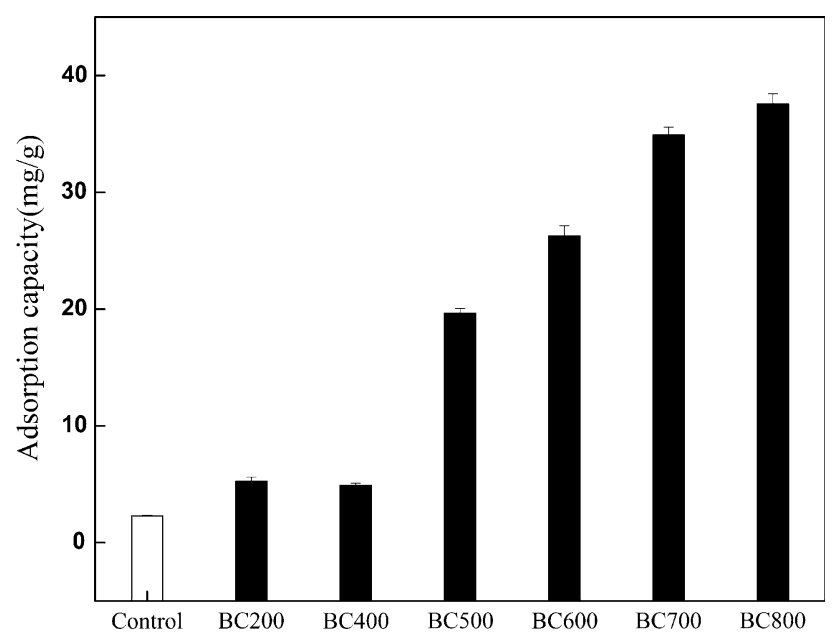

Fig. 1 Adsorption capacity of AMBC

enhancement in the adsorption capacity, with a significant increase in the removal efficiency when carbonization at $500{ }^{\circ} \mathrm{C}(19.65 \pm 0.41 \mathrm{mg} / \mathrm{g})$. BC800 had the highest adsorption capacity $\left(q_{\mathrm{e}}=37.6 \pm 0.87 \mathrm{mg} / \mathrm{g}\right.$, CIP concentration $100 \mathrm{mg} / \mathrm{L}$ ) compared with the other pyrolysis temperatures. In the following study, BC800 with the highest $\mathrm{q}_{\mathrm{e}}$ was selected as the adsorbent because of its excellent performance for CIP adsorption in the present study.

\section{Characterization of AMBC}

Biochar has proved to be effective for the adsorption of organic pollutants because of its high surface area and micropore structure (Inyang and Dickenson 2015). Previous studies showed that biochar produced at temperatures higher than $400{ }^{\circ} \mathrm{C}$ had better adsorption capacity (Ahmad et al. 2014). In this research, the $S_{\mathrm{BET}}$ and SEM images also proved that pyrolysis temperature produces a significant enhancement of AMBC characteristics. For example, the BET surface area ranged from $0.42 \mathrm{~m}^{2} / \mathrm{g}$ (natural residue) to $176.33 \mathrm{~m}^{2} / \mathrm{g}$ (BC800). This significant increase in $S_{\mathrm{BET}}$ (approximately 420-fold) could be attributed to the pores in the biochar as shown in Fig. 2. The results demonstrated that a large BET surface area can offer more active adsorption sites for CIP by increasing the adsorption capacity (BC800 had the highest $q_{e}$ ).

The surface area characteristics, proximate analysis and carbon, hydrogen, oxygen and nitrogen content of biochar are given in Table 1 . The proximate analysis gives the ash,

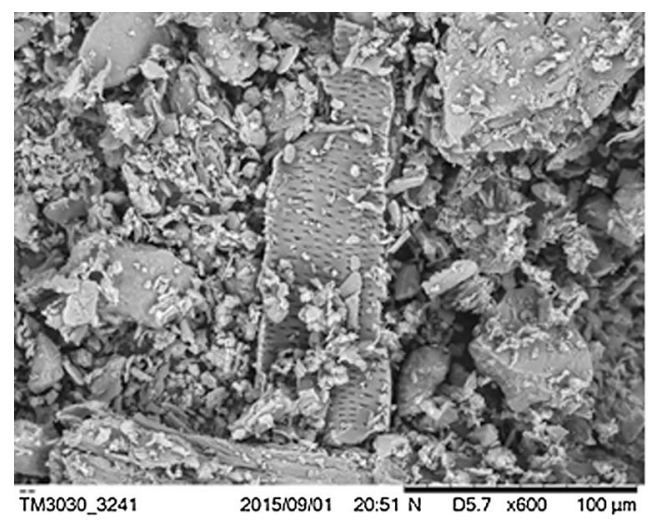

(a)

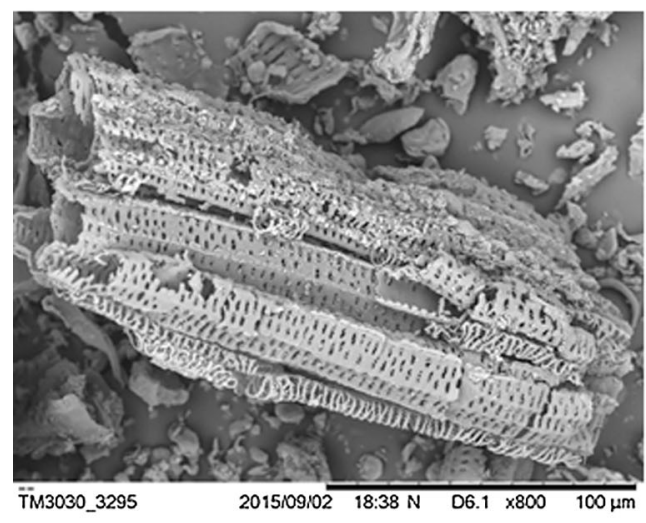

(c)

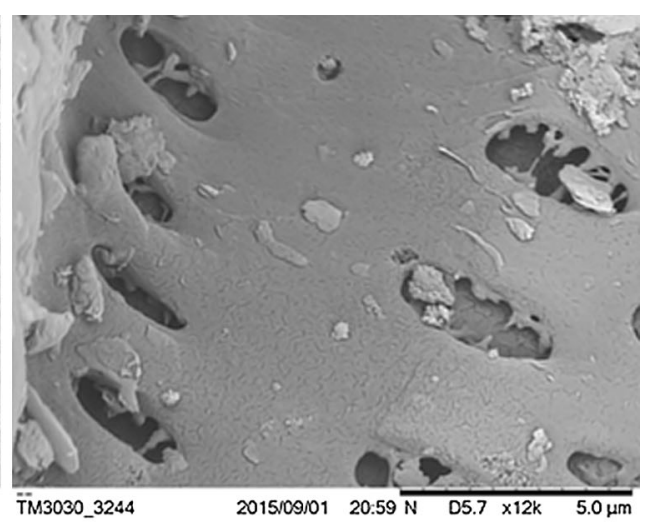

(b)

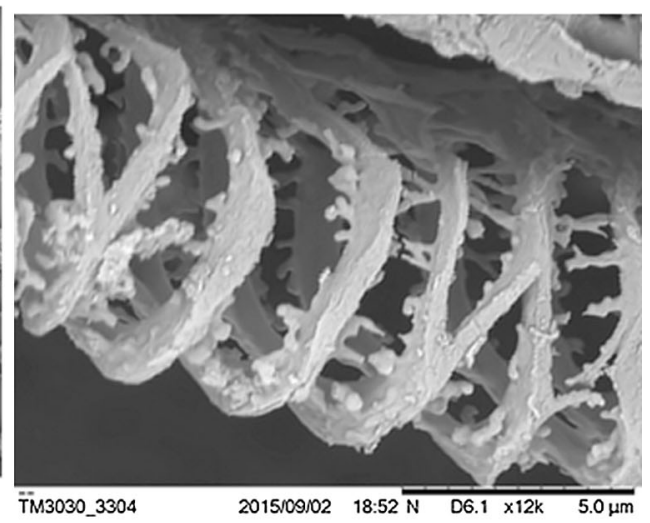

(d)

Fig. 2 SEM images of A. mongholicus residue (a, b) and BC800 (c, d) 
Table 1 Properties of biochar derived from A. mongholicus at $800{ }^{\circ} \mathrm{C}$

\begin{tabular}{ll}
\hline Properties of BC800 and Astragalus mongholicus \\
Surface area characteristics \\
$S_{\mathrm{BET}}\left(\mathrm{m}^{2} / \mathrm{g}\right)^{\mathrm{b}}$ & $176.33(0.42)$ \\
$S_{\mathrm{mic}}\left(\mathrm{m}^{2} / \mathrm{g}\right)^{\mathrm{c}}$ & $100.76(\mathrm{ND})^{\mathrm{d}}$ \\
$S_{\mathrm{min}} / S_{\mathrm{BET}}(\%)$ & 57.14 \\
$V_{\mathrm{T}}\left(\mathrm{cm}^{3} / \mathrm{g}\right)^{\mathrm{e}}$ & $0.1399(0.0077)$ \\
$V_{\mathrm{mic}}\left(\mathrm{cm}^{3} / \mathrm{g}\right)^{\mathrm{f}}$ & $0.044(\mathrm{ND})$ \\
$\mathrm{V}_{\mathrm{mic}} / V_{\mathrm{T}}(\%)$ & 31.53 \\
Elemental analysis & \\
$\mathrm{C}(\%)$ & $57.76(41.74)$ \\
$\mathrm{H}(\%)$ & $0.975(4.994)$ \\
$\mathrm{O}(\%)$ & $15.13(44.13)$ \\
$\mathrm{N}(\%)$ & $1.66(1.5)$ \\
Proximate analysis & $2.5(6.84)$ \\
Moisture $(\%)$ & $32.2(9.76)$ \\
Ash $(\%)$ & $10.21(71.11)$ \\
Volatile $(\%)$ & $55.09(12.29)$ \\
Fixed carbon $(\%)$ & \\
\hline a Values in the parenthesis are for natural A. mongholicus residue \\
b Surface area measured using $\mathrm{N}_{2}$ adsorption with the BET method \\
c Micropore surface area calculated using the $t$-plot method \\
d The value was too small to measure \\
e Total pore volume \\
f Micropore volume calculated with the $t$-plot method \\
\hline
\end{tabular}

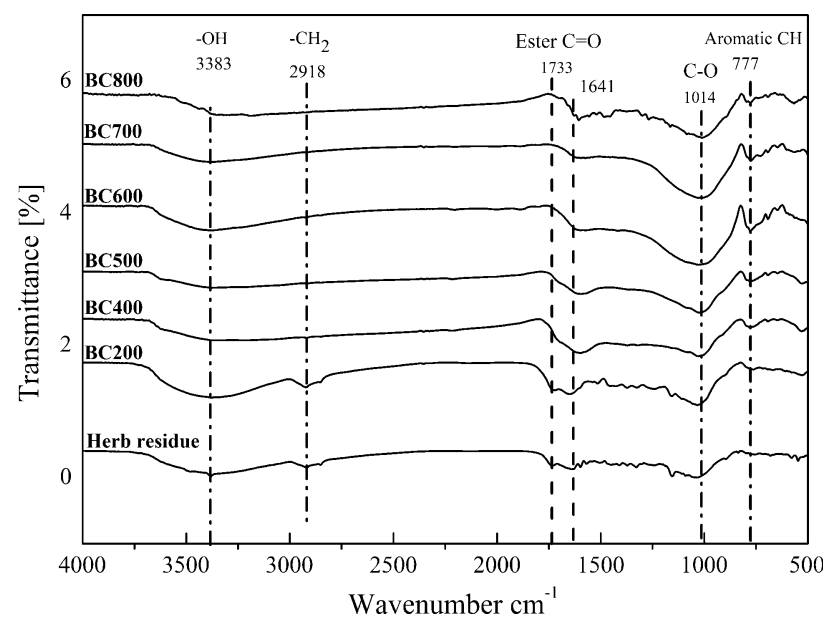

Fig. 3 FTIR spectra of the nature A. mongholicus residues and biochar

volatile and fixed carbon contents of biochar. Elemental C, $\mathrm{H}$ and $\mathrm{N}$ content was determined by combustion. Oxygen was determined by difference. FTIR spectra for natural $A$. mongholicus residues and Biochar were measured in the $4000-500 \mathrm{~cm}^{-1}$ region (Fig. 3). The results were consistent with the previous research (Zheng et al. 2013). Various bands in the FTIR spectra represent band vibrations in the biochars: $\mathrm{O}-\mathrm{H} \quad\left(3000-3690 \mathrm{~cm}^{-1}\right)$, aliphatic $\mathrm{C}-\mathrm{H}$ $\left(2918 \mathrm{~cm}^{-1}\right)$, ester $\mathrm{C}=\mathrm{O}\left(1733 \mathrm{~cm}^{-1}\right)$, polymeric $\mathrm{CH}_{2}$ $\left(1641 \mathrm{~cm}^{-1}\right), \quad \mathrm{C}-\mathrm{O} \quad\left(1014 \mathrm{~cm}^{-1}\right)$ and aromatic $\mathrm{C}-\mathrm{H}$ $\left(777 \mathrm{~cm}^{-1}\right)$. The FTIR spectra indicated that carbonization temperature has a significant influence on the functional groups of biochars.

The XPS spectra of the C1s electrons are shown in Fig. 4. The C1s functional groups were characterized according to previously published studies, and the present results closely matched those of previous studies (Azargohar et al. 2014; Singh et al. 2014; Liu et al. 2015). The peak at $284.8 \mathrm{eV}$ was assigned to carbon components, such as $\mathrm{C}-\mathrm{C}, \mathrm{C}=\mathrm{C}$, aromatic and aliphatic carbon, the $286.4 \mathrm{eV}$ peak was assigned to $\mathrm{C}-\mathrm{O}-\mathrm{C}$, and 288.9 Ev was assigned to COO. The functional groups that contain the oxygen mentioned above may react with CIP by various mechanisms, such as hydrophobic, $\mathrm{H}$-bond and $\pi-\pi$ interactions, thereby increasing the adsorption capacity of AMBC (Inyang and Dickenson 2015).

\section{Effect of adsorbent dosage and solution $\mathrm{pH}$}

The impact of adsorbent dosage on CIP removal efficiency and adsorption capacity $\left(q_{\mathrm{e}}\right)$ was investigated at an initial concentration of $100 \mathrm{mg} / \mathrm{L}$. An increase in the adsorbent dosage from 25 to $500 \mathrm{mg}$ significantly increased the CIP removal efficiency from 36 to $100 \%$. This improvement can be attributed to the great number of adsorption sites and the larger surface area caused by the increased biochar

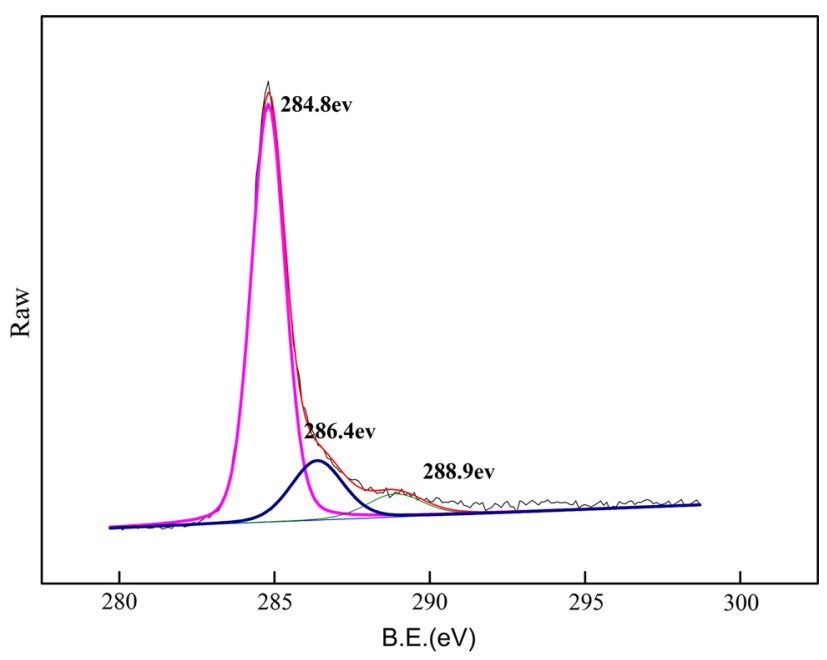

Fig. 4 XPS spectra of C1s of AMBC (800) 


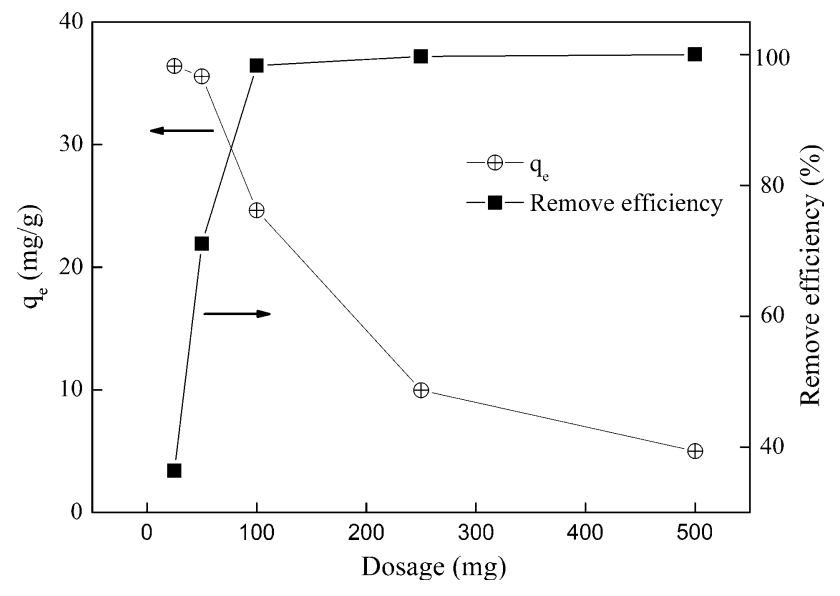

Fig. 5 Effect of biochar dosage on removal efficiency and $q_{\mathrm{e}}$

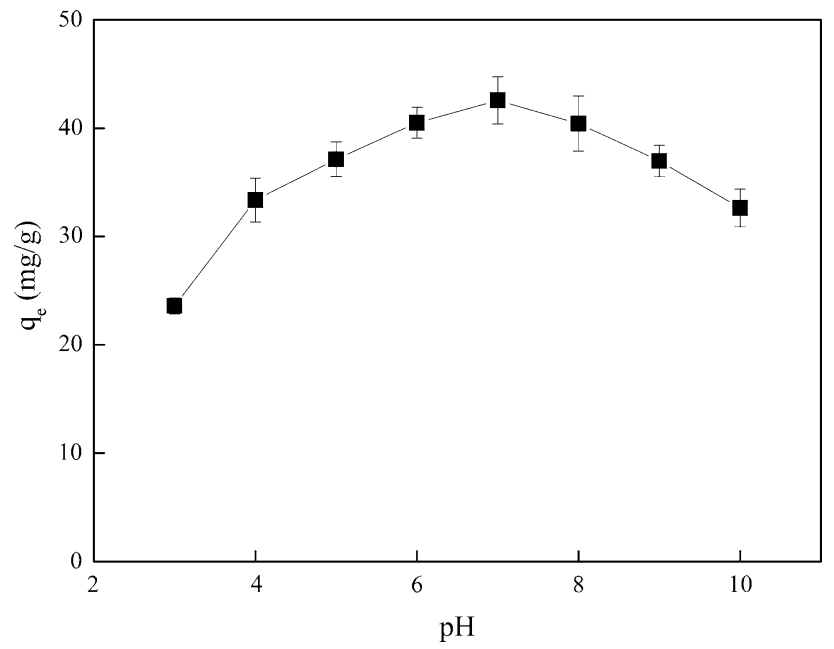

Fig. 6 Effect of solution pH on biochar adsorption capacity $\left(q_{\mathrm{e}}\right)$

dosage (Adamczuk and Kołodyńska 2015). However, qe decreased with the increase in biochar dosage because of the increase in unsaturated adsorption sites on the $\mathrm{BC}$ surface. Based on these results (Fig. 5), the following batch experiments were conducted at an adsorbent dosage of $50 \mathrm{mg}$ with $25 \mathrm{~mL}$ CIP solution $(\mathrm{m} / v=1: 500)$.

The $\mathrm{pH}$ of the solution is one of the most important control parameters in the adsorption process. The effects of $\mathrm{pH}$ were investigated, and the results are shown in Fig. 6. The results demonstrated that with a $\mathrm{pH}$ increase from 3 to 7 , the adsorption capacity of biochar increased, whereas the adsorption capacity of biochar decreased with the change from $\mathrm{pH} 7$ to 10 . Previous studies have proven that the effects of $\mathrm{pH}$ were dependent on both the biochar surface properties and the adsorbate pollutant characteristics. For example, the functional groups on the surface of biochar change with the $\mathrm{pH}$; published studies have also demonstrated that there are different ionizations and degrees of ionization of CIP under different $\mathrm{pH}$ conditions ( $\mathrm{Li}$ et al. 2014). Because CIP molecules contain several moieties, such as $\mathrm{NH}_{2}$ and $\mathrm{COOH}$ groups, hydrophilic CIP exists as the cation $\left(\mathrm{CIP}^{+}\right)$, anion $\left(\mathrm{CIP}^{-}\right)$, uncharged molecule $\left(\mathrm{CIP}^{0}\right)$ and zwitterion $\left(\mathrm{CIP}^{ \pm}\right)$in water (CIP: $\mathrm{pKa}=6.2$ and $\mathrm{p} K \mathrm{a} 2=8.8$ ). Thus, the removal of CIP can be attributed to the formation of H-bonding between CIP and biochar, depending on the $\mathrm{pH}$ of the solution (Jing et al. 2014), thus possibly presenting another reason for the importance of $\mathrm{pH}$ as one of the most important control factors in the present study.

\section{Adsorption isotherms}

Four isotherm models (Langmuir, Freundlich, Temkin and Dubinin-Radushkevich (D-R) isotherms) were tested in the present research to evaluate the maximum $\mathrm{q}_{\mathrm{e}}$ and understand the mechanism of adsorption of CIP onto AMBC (Fig. 7). The results presented in Fig. 7 and Table 2 demonstrate that the adsorption data can be described better by the Langmuir isotherm $\left(\mathrm{R}^{2}, 0.999\right)$ than by the Freundlich isotherm $\left(\mathrm{R}^{2}, 0.983\right)$, Temkin isotherm $\left(\mathrm{R}^{2}, 0.983\right)$ or $\mathrm{D}-\mathrm{R}$ isotherm $\left(\mathrm{R}^{2}, 0.878\right)$. Similar results were reported for adsorption of persistent organic pollutants, antibiotics and other organic pollutants with carbonaceous materials, such as active carbon, biochar or carbon nanotubes (Carabineiro et al. 2012; Zheng et al. 2013; Essandoh et al. 2015; Ma et al. 2015; Mita et al. 2015).

The essential features of the Langmuir equation can be expressed in terms of a dimensionless constant separation factor $\left(R_{\mathrm{L}}\right)$ as defined by McKay (1982):

$R_{\mathrm{L}}=\frac{1}{1+k_{\mathrm{a}} C_{0}}$

where $C_{0}$ is the highest initial CIP concentration $(\mathrm{mg} / \mathrm{L})$. The value of $R_{\mathrm{L}}$ indicates whether the shape of the isotherm is irreversible $\left(R_{\mathrm{L}}=0\right)$, favorable $\left(0<R_{\mathrm{L}}<1\right)$, linear $\left(R_{\mathrm{L}}=1\right)$ or unfavorable $\left(R_{\mathrm{L}}>1\right)$.

$R_{\mathrm{L}}$ was 0.009 in this study, showing that the adsorption behavior of CIP was favorable. According to the Freundlich isotherm model, the value of $\mathrm{n}$ was 6.821 and that 
Fig. 7 Adsorption isotherms of CIP on BC800
Table 2 Isotherm model parameters for the adsorption of CIP by BC
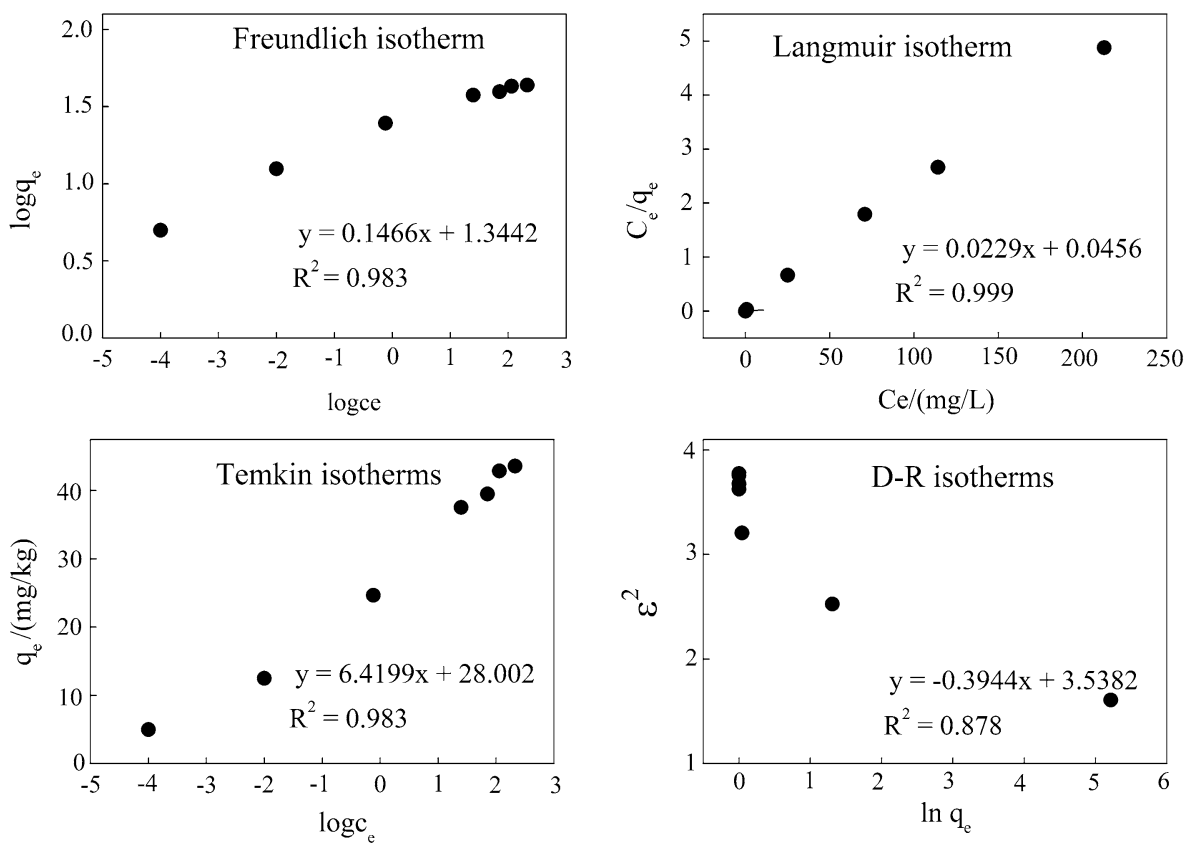

Table 3 Adsorption capacities of different carbonaceous adsorbents for adsorption of antibiotics

\begin{tabular}{llllllll}
\hline \multicolumn{2}{l}{ Freundlich } & Langmuir & \multicolumn{3}{c}{ Temkin } \\
\hline$K_{\mathrm{f}}$ & 3.835 & $q_{\mathrm{m}}(\mathrm{mg} / \mathrm{g})$ & 43.668 & $B_{1}(\mathrm{~J} / \mathrm{mol})$ & 7.363 & $q_{\mathrm{m}}(\mathrm{mg} / \mathrm{g})$ & 36.551 \\
$n$ & 6.821 & $K_{\mathrm{a}}(\mathrm{L} / \mathrm{mg})$ & 0.502 & $k_{\mathrm{t}}$ & 44.834 & $E(\mathrm{~kJ} / \mathrm{mol})$ & 11.259 \\
$R^{2}$ & 0.983 & $R^{2}$ & 0.999 & $R^{2}$ & 0.983 & $R^{2}$ & 0.878 \\
\hline
\end{tabular}

\begin{tabular}{llll}
\hline Type of biochar & Pollutants $^{\mathrm{a}}$ & $q_{\mathrm{e}}(\mathrm{mg} / \mathrm{g})^{\mathrm{b}}$ & References \\
\hline Plant biochar & SMT & 37.7 & Rajapaksha et al. (2015) \\
Agricultural soil biochar & SMX & $4.99 \pm 0.74$ & Zheng et al. (2013) \\
Cow manure biochar & SMT & 10.87 & Tzeng et al. (2016) \\
Wastewater sludge biochar & GAT & 19.80 & Yao et al. (2013) \\
Herb biochar & CIP & 42.9 & This study \\
Activated carbon & CIP & 231 & Carabineiro et al. (2012) \\
Carbon nanotubes & CIP & 209.6 & Yu et al. (2016) \\
Graphene & CIP & 235.6 & Ma et al. (2015) \\
Graphene & CIP & 194.6 & Yu et al. (2015) \\
\hline
\end{tabular}

a $S M T$ sulfamethazine, SMX sulfamethoxazole, GAT gatifloxacin, CIP ciprofloxacin

b $q_{\mathrm{e}}$ is the maximum adsorption capacity

c CIP concentration $200 \mathrm{mg} / \mathrm{L}$

of $K_{\mathrm{f}}$ was 3.835 , also indicating that the adsorption conditions for $\mathrm{BC}$ were favorable for CIP. The $\mathrm{E}$ value $(11.259 \mathrm{~kJ} / \mathrm{mol})$ was found to be in the range of $8-16 \mathrm{~kJ} / \mathrm{mol}$, which further indicates that the type of adsorption of CIP on biochar is a chemical process (Ma et al. 2015). The result is consistent with the report of sulfamethazine chemical sorption on plant-derived biochar (Rajapaksha et al. 2015), the removal of ciprofloxacin with 


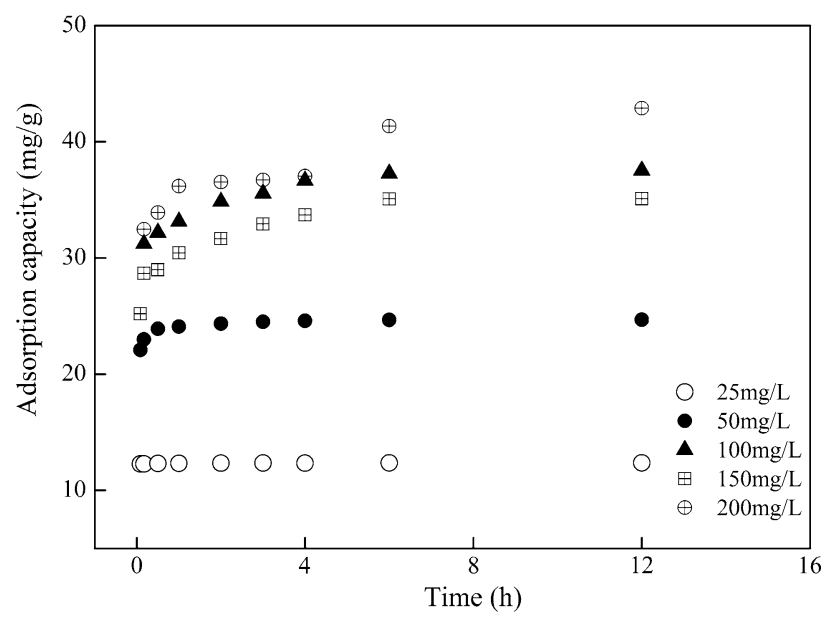

Fig. 8 Influence of contact time on $q_{\mathrm{e}}$

activated carbon (Huang et al. 2014) and the removal of sulfamethoxazole with biochar prepared from agricultural soil (Zheng et al. 2013), as briefly summarized in Table 3.

Various mechanisms, such as hydrophobic, electrostatic, hydrogen bond and $\pi-\pi$ interactions, may simultaneously participate in the antibiotic adsorption processes (Mohan et al. 2014). CIP may interact with adsorbent via $\pi-\pi$ EDA (electron donor-acceptor) interactions because the benzene rings have a fluorine group and an N-heteroaromatic ring. The $\pi-\pi$ interaction has previously been verified as one of the most important driving forces for the sorption of organic pollutants onto biochar (Ahmad et al. 2014) and carbon nanomaterials adsorbent ( $\mathrm{Li}$ et al. 2014; Yu et al. 2016).

\section{Adsorption kinetics}

Kinetics experiments that were conducted with different initial concentrations with the time ranging from $1 \mathrm{~h}$ to $12 \mathrm{~h}$ are presented in Fig. 8. The adsorption capacity increased with time, and $12 \mathrm{~h}$ was considered the equilibrium time (Fig. 8).

The pseudo-first-order and pseudo-second-order models were used to test for the adsorption of CIP onto BC800 to evaluate the adsorption kinetics parameters. These parameters are important for predicting the adsorption capacity and estimating the adsorption rates when designing adsorption columns. Table 4 presents the kinetic parameters of the pseudo-first-order and pseudo-second-order models, including the constants $k_{1}, k_{2}$, calculated adsorption capacities $q_{\mathrm{e}, \mathrm{cal}}$ and $R^{2}$. The value of $R^{2}$ proved that the pseudo-second-order kinetic model $(>0.999)$ is a better fitting model for the adsorption of CIP onto BC800. The calculated $q_{\mathrm{e}}$ in the pseudo-second-order model is also in agreement with the experimental adsorption capacity, indicating that adsorption of CIP with biochar is a chemical process (Ho and McKay 1999; Yu et al. 2015).

\section{Conclusion}

In the present research, a batch adsorption study for the adsorption of CIP with A. mongholicus residue biochar was conducted. The characteristics of AMBC were examined at different initial CIP concentrations, contact times and $\mathrm{pH}$ values. The results demonstrated that the A. mongholicus biochar can be used as an effective low-cost adsorbent for removal of CIP. The adsorption capacity of AMBC was found to increase with an increase in temperature. $\mathrm{BC} 800$ was observed to have the maximum adsorption capacity, whereas natural A. mongholicus had the lowest adsorption capacity. The adsorption was $\mathrm{pH}$ dependent, and the maximum $\mathrm{q}_{\mathrm{e}}$ was found to occur at $\mathrm{pH}$ 7. The adsorption of CIP on AMBC is a chemical process and was found to follow the pseudo-second-order model. The Langmuir adsorption model was a better fit for the adsorption process than the Freundlich isotherms was.
Table 4 Kinetic parameters of adsorption kinetics

\begin{tabular}{|c|c|c|c|c|c|c|c|}
\hline \multirow[t]{2}{*}{$C_{0}(\mathrm{mg} / \mathrm{L})$} & \multirow[t]{2}{*}{$q_{\mathrm{e}}(\mathrm{mg} / \mathrm{g})$} & \multicolumn{3}{|c|}{ Pseudo-first-order kinetics } & \multicolumn{3}{|c|}{ Pseudo-second-order kinetics } \\
\hline & & $q_{\mathrm{e}, \mathrm{cal}}(\mathrm{mg} / \mathrm{g})$ & $k_{1}\left(\min ^{-1}\right)$ & $R^{2}$ & $q_{\mathrm{e}, \mathrm{cal}}(\mathrm{mg} / \mathrm{g})$ & $k_{2}\left(\min ^{-1}\right)$ & $R^{2}$ \\
\hline 25 & 12.38 & 0.33 & 0.15 & 0.758 & 12.38 & 32.64 & 0.999 \\
\hline 50 & 24.68 & 1.70 & 0.79 & 0.941 & 24.75 & 2.04 & 0.999 \\
\hline 100 & 37.54 & 9.31 & 0.64 & 0.980 & 37.74 & 0.23 & 0.999 \\
\hline 200 & 42.90 & 10.96 & 0.12 & 0.816 & 43.29 & 0.08 & 0.999 \\
\hline
\end{tabular}


Acknowledgements This work was supported by the Natural Science Foundation of Jiangsu Province (CN) (BK20150693, BK20140657), the Open Foundation of State Key Laboratory of Lake Science and Environment, CAS (No. 2014SKL005), and the fund for Fostering Talents of Basic Science (NFFTBS) (J1030830).

\section{References}

Adamczuk A, Kołodyńska D (2015) Equilibrium, thermodynamic and kinetic studies on removal of chromium, copper, zinc and arsenic from aqueous solutions onto fly ash coated by chitosan. Chem Eng J 274:200-212

Ahmad M, Rajapaksha AU, Lim JE, Zhang M, Bolan N, Mohan D, Vithanage M, Lee SS, Ok YS (2014) Biochar as a sorbent for contaminant management in soil and water: a review. Chemosphere 99:19-33

Ali I, Asim M, Khan TA (2012) Low cost adsorbents for the removal of organic pollutants from wastewater. J Environ Manage 113:170-183

Azargohar R, Nanda S, Kozinski JA, Dalai AK, Sutarto R (2014) Effects of temperature on the physicochemical characteristics of fast pyrolysis bio-chars derived from Canadian waste biomass. Fuel 125:90-100

Carabineiro S, Thavorn-Amornsri T, Pereira M, Serp P, Figueiredo J (2012) Comparison between activated carbon, carbon xerogel and carbon nanotubes for the adsorption of the antibiotic ciprofloxacin. Catal Today 186(1):29-34

Chen T, Zhou Z, Han R, Meng R, Wang H, Lu W (2015) Adsorption of cadmium by biochar derived from municipal sewage sludge: impact factors and adsorption mechanism. Chemosphere 134:286-293

Dubey A, Mishra A, Singhal S (2014) Application of dried plant biomass as novel low-cost adsorbent for removal of cadmium from aqueous solution. Int $\mathbf{J}$ Environ Sci Technol 11(4): 1043-1050

Essandoh M, Kunwar B, Pittman CU, Mohan D, Mlsna T (2015) Sorptive removal of salicylic acid and ibuprofen from aqueous solutions using pine wood fast pyrolysis biochar. Chem Eng J 265:219-227

Gao S, Zhao Z, Xu Y, Tian J, Qi H, Lin W, Cui F (2014) Oxidation of sulfamethoxazole (SMX) by chlorine, ozone and permanganate-a comparative study. J Hazard Mater 274:258-269

Ho Y-S, McKay G (1999) Pseudo-second order model for sorption processes. Process Biochem 34(5):451-465

Huang L, Wang M, Shi C, Huang J, Zhang B (2014) Adsorption of tetracycline and ciprofloxacin on activated carbon prepared from lignin with $\mathrm{H}_{3} \mathrm{PO}_{4}$ activation. Desalin Water Treat 52(13-15):2678-2687

Inyang M, Dickenson E (2015) The potential role of biochar in the removal of organic and microbial contaminants from potable and reuse water: a review. Chemosphere 134:232-240

Jing XR, Wang YY, Liu WJ, Wang YK, Jiang H (2014) Enhanced adsorption performance of tetracycline in aqueous solutions by methanol-modified biochar. Chem Eng J 248:168-174

Komkiene J, Baltrenaite E (2016) Biochar as adsorbent for removal of heavy metal ions [Cadmium (II), Copper (II), Lead (II), Zinc (II)] from aqueous phase. Int $\mathrm{J}$ Environ Sci Technol 13(2):471-482
Le-Minh N, Stuetz RM, Khan SJ (2012) Determination of six sulfonamide antibiotics, two metabolites and trimethoprim in wastewater by isotope dilution liquid chromatography/tandem mass spectrometry. Talanta 89:407-416

Li H, Zhang D, Han X, Xing B (2014) Adsorption of antibiotic ciprofloxacin on carbon nanotubes: $\mathrm{pH}$ dependence and thermodynamics. Chemosphere 95:150-155

Liu N, Charrua AB, Weng C-H, Yuan X, Ding F (2015) Characterization of biochars derived from agriculture wastes and their adsorptive removal of atrazine from aqueous solution: a comparative study. Bioresour Technol 198:55-62

Loow Y-L, Wu TY, Tan KA, Lim YS, Siow LF, Md Jahim J, Mohammad AW, Teoh WH (2015) Recent advances in the application of inorganic salt pretreatment for transforming lignocellulosic biomass into reducing sugars. J Agric Food Chem 63(38):8349-8363

Ma J, Yang M, Yu F, Zheng J (2015) Water-enhanced removal of ciprofloxacin from water by porous graphene hydrogel. Sci Rep 5:13578

McKay G (1982) Adsorption of dyestuffs from aqueous solutions with activated carbon I: equilibrium and batch contact-time studies. J Chem Technol Biotechnol 32(7-12):759-772

Mita L, Grumiro L, Rossi S, Bianco C, Defez R, Gallo P, Mita DG, Diano N (2015) Bisphenol A removal by a Pseudomonas aeruginosa immobilized on granular activated carbon and operating in a fluidized bed reactor. J Hazard Mater 291:129-135

Mohan D, Sarswat A, Ok YS, Pittman CU (2014) Organic and inorganic contaminants removal from water with biochar, a renewable, low cost and sustainable adsorbent-a critical review. Bioresour Technol 160:191-202

Mui EL, Cheung W, Valix M, McKay G (2010) Dye adsorption onto char from bamboo. J Hazard Mater 177(1-3):1001-1005

Qiu G, Song Y, Zeng P, Duan L, Xiao S (2013) Characterization of bacterial communities in hybrid upflow anaerobic sludge blanket (UASB)-membrane bioreactor (MBR) process for berberine antibiotic wastewater treatment. Bioresour Technol 142:52-62

Rajapaksha AU, Vithanage M, Ahmad M, Seo DC, Cho JS, Lee SE, Lee SS, Ok YS (2015) Enhanced sulfamethazine removal by steam-activated invasive plant-derived biochar. J Hazard Mater 290:43-50

Shang J, He W, Fan C (2015) Adsorption of dimethyl trisulfide from aqueous solution on a low-cost adsorbent: thermally activated pinecone. Chin J Oceanol Limnol 33(1):169-175

Singh B, Fang Y, Cowie BC, Thomsen L (2014) NEXAFS and XPS characterisation of carbon functional groups of fresh and aged biochars. Org Geochem 77:1-10

Sun L, Wan S, Luo W (2013) Biochars prepared from anaerobic digestion residue, palm bark, and eucalyptus for adsorption of cationic methylene blue dye: characterization, equilibrium, and kinetic studies. Bioresour Technol 140:406-413

Thiele-Bruhn S (2003) Pharmaceutical antibiotic compounds in soils-a review. J Plant Nutr Soil Sci 166(2):145-167

Tzeng TW, Liu YT, Deng Y, Hsieh YC, Tan CC, Wang SL, Huang ST, Tzou YM (2016) Removal of sulfamethazine antibiotics using cow manure-based carbon adsorbents. Int J Environ Sci Technol 13(3):973-984

Wang D, Sui Q, Zhao WT, Lv SG, Qiu ZF, Yu G (2014) Pharmaceutical and personal care products in the surface water of China: A review (in Chinese). Chin Sci Bull (Chin Version) 59(9):743-751 
Wang MC, Sheng GD, Qiu YP (2015) A novel manganese-oxide/ biochar composite for efficient removal of lead (II) from aqueous solutions. Int J Environ Sci Technol 12(5):1719-1726

Yao H, Lu J, Wu J, Lu Z, Wilson PC, Shen Y (2013) Adsorption of fluoroquinolone antibiotics by wastewater sludge biochar: role of the sludge source. Water Air Soil Pollut 224(1):1-9

Yu F, Ma J, Bi D (2015) Enhanced adsorptive removal of selected pharmaceutical antibiotics from aqueous solution by activated graphene. Environ Sci Pollut Res 22(6):4715-4724

Yu F, Sun S, Han S, Zheng J, Ma J (2016) Adsorption removal of ciprofloxacin by multi-walled carbon nanotubes with different oxygen contents from aqueous solutions. Chem Eng J 285:588-595
Zhang Q-Q, Ying G-G, Pan C-G, Liu YS, Zhao JL (2015) Comprehensive evaluation of antibiotics emission and fate in the river basins of China: source analysis, multimedia modelling, and linkage to bacterial resistance. Environ Sci Technol 49(11):6772-6782

Zheng H, Wang Z, Zhao J, Herbert S, Xing B (2013) Sorption of antibiotic sulfamethoxazole varies with biochars produced at different temperatures. Environ Pollut 181:60-67

Zhou J, Broodbank N (2014) Sediment-water interactions of pharmaceutical residues in the river environment. Water Res 48:61-70 